\title{
El Código de Ética Profesional del Contador Público en Perú y México
}

\section{The Professional Code of Ethics of the Public Accountant in Peru and Mexico}

DOI: http://dx.doi.org/10.17981/econcuc.39.2.2018.07

Artículo de investigación. Fecha de recepción: 28/09/2018 Fecha de aceptación: 23/10/2018

\author{
Enriqueta Mancilla-Rendón \\ Universidad La Salle (México) \\ maenriqueta.mancilla@ulsa.mx
}

\author{
Oscar Alfredo Díaz-Becerra (iD \\ Pontificia Universidad Católica del Perú (Perú) \\ odiaz@pucp.edu.pe
}

\section{Lorenza Morales Alvarado \\ Universidad Continental (Perú) lmorales@continental.edu.pe}

Para citar este artículo:

Mancilla-Rendón, E., Díaz-Becerra, A. y Morales, L. (2018). El Código de Ética Profesional del Contador Público en Perú y México. Económicas CUC, 39(2). 109-128. DOI: http://dx.doi.org/10.17981/econcuc.39.2.2018.07

\section{Resumen}

La ética en las organizaciones implica un estudio de distintas variables, aquellas vinculadas al comportamiento del ser humano, así como las vinculadas al entorno en que este se desenvuelve. La investigación tiene un carácter descriptivo y tiene como objetivo desarrollar un estudio comparativo de las normas legales y contables vinculadas al Código de Ética profesional del contador público en Perú y México para comprender la probable incidencia con la responsabilidad social empresarial. El estudio aborda el análisis de la normatividad legal y gremial del Contador Público, con una revisión general del Código emitido por International Federation of Accountants (IFAC). El trabajo se respalda en una revisión de la literatura relevante, sobre la base de conceptos en que se percibe la aplicación de los valores éticos por normas legales y normas contables, vinculando sus efectos con la responsabilidad social que tienen las empresas producto del desarrollo de sus operaciones.

Palabras clave: Código de ética profesional, conflicto de interés, juicio profesional, transparencia, corrupción.

\section{Abstract}

Ethics in organizations implies a study of different variables, those linked to the behavior of the human being, as well as those related to the environment in which it operates. The research has a descriptive character and aims to develop a comparative study of the legal and accounting standards linked to the Code of Professional Ethics of the public accountant in Peru and Mexico to understand the likely incidence with corporate social responsibility. The study addresses the analysis of the legal and union regulations of the Public Accountant, with a general review of the Code issued by IFAC. The work is supported by a review of the relevant literature, based on concepts in which the application of ethical values is perceived by legal norms and accounting standards, linking their effects with the social responsibility that companies have as a result of the development of their operations.

Keywords: Code of professional ethics, conflict of interest, professional judgment, transparency, corruption. 


\section{Introducción}

Es preocupante y desalentador el aumento de publicaciones relacionadas con la pérdida de valores y actos de corrupción que afectan a nuestra sociedad. Mucha de esta información tiene que ver con las prohibiciones de hacer y de no hacer, y se asocia al comportamiento moral de las personas y al papel de las diversas instituciones en la búsqueda de sus objetivos. Es en este contexto que observamos el efecto de la forma como se conducen las personas y las actitudes que presentan, según lo que requieren las circunstancias. Tal como afirma Brown (1992), encontramos "individuos que utilizan su situación dentro de las instituciones para obtener ventajas egoístas". También encontramos instituciones que provocan menoscabo al "ambiente social y natural", y en ocasiones, sitios en donde se puede apreciar el "sufrimiento que las instituciones imponen a sus propios empleados y gerentes" (p. 19).

Otro concepto que se relaciona con los principios Éticos, es la corrupción. La descomposición de la sociedad, y, por ende, de las organizaciones, tiene incidencia sobre la optimización de los recursos naturales, económicos, materiales, y por supuesto, en la distribución de la riqueza y en la calidad de vida de la sociedad. El Fondo Monetario Internacional citado por Wolf y Gürgen (2012) definen a la corrupción como "el abuso de la autoridad o de la confianza para el beneficio privado, y es una tentación en la que caen no sólo los funcionarios públicos, sino también las personas que ocupan puestos de confianza o de autoridad en la empresa privada, o en organizaciones sin fines de lucro" (p. 3).

En relación a este entorno, el contador público trabaja en contacto directo con la gerencia o la alta dirección, ocupando cargos de confianza, es por ello, que su papel como emisor de la información financiera tiene impacto social y ético para los gru- pos de interés. En tal sentido, se realiza un estudio comparativo de la regulación del gremio profesional en relación al comportamiento ético del Contador Público en Perú y México, y su relación con la actividad empresarial.

Por estas razones, la ética en las organizaciones, pasa a diferenciarse en tres niveles. En el primero de ellos se plantea como los principios éticos y valores de las personas, al interior de las organizaciones, inciden en el ámbito de la responsabilidad social empresarial. Responsabilidad social empresarial comprendida como "la formalización de políticas y sistemas de gestión en los ámbitos económico, social y medioambiental; la transparencia informativa de los resultados de dichos ámbitos y el escrutinio externo de los mismos" (Chumaceiro y Hernández, 2016, p. 106). En un segundo nivel nos encontramos ante la discriminación en la calificación de algunas empresas al ser mejor calificadas éticamente con respecto a otras. El tercer nivel aborda la interrogante referida a si los valores de las instituciones, o los valores de las personas, coadyuvan a clasificar a las empresas como responsables socialmente.

El presente estudio procede a comparar las normas legales y contables vinculadas al Código de Ética del Contador Público en Perú y México, e identificar su incidencia en la responsabilidad social empresarial. Asimismo, conlleva cuatro objetivos, entre los cuales tenemos: El primero es analizar las normas que regulan el ejercicio profesional del contador público en Perú y México. En segundo lugar, se busca identificar las causas por las cuales las empresas están mejor calificadas éticamente en Perú y México. El tercer objetivo plantea identificar el tipo de valores, institucionales o personales, que coadyuvan a clasificar a las empresas como responsables socialmente. El último objetivo propone analizar los principales problemas éticos que afectan la actividad empresarial. 
El estudio sobre la normatividad y el impacto del comportamiento ético de los individuos, cobra mayor relevancia en la coyuntura actual, donde el fraude y la corrupción han copado todos los niveles, desde las instituciones gubernamentales y partidos políticos, hasta las operaciones cotidianas del sector empresarial privado, afectando el sistema económico y político de varios países, en particular, en Latinoamérica. Estos países se han visto afectados por lo que se considera los mayores escándalos de corrupción de las últimas décadas, lo cual resalta la importancia de llevar a cabo estudios que identifiquen el comportamiento ético en estas situaciones. En este contexto, la contabilidad juega un papel importante, y por lo tanto, el ejercicio profesional del contador público se ve estrechamente relacionado, motivando el análisis del marco legal en el que se desenvuelve.

\section{Metodología}

La investigación tiene un alcance descriptivo-transversal, realizado con técnicas de investigación crítica-documental, en el que se hace un estudio comparativo del Código de Ética Profesional del Contador Público aplicado en Perú y México, y la normatividad nacional vinculada a él, emitida por las instituciones del gremio de la contaduría y las instituciones legislativas. Se realiza una revisión hermenéutica crítica "que sostiene que la interpretación se encuentra limitada y sesgada por fuerzas sociales, políticas y económicas" (Alvarez-Gayou, 2003, p. 83) de códigos fiscales, leyes y reglamentos, normas contables, y principios teóricos vinculantes al Código de Ética Profesional que emite el International Federation of Accountants (IFAC). Se fundamenta con la doctrina de legislaciones especializadas que regulan el derecho fiscal y mercantil. También se estudia la responsabilidad social empresarial de algunos grupos corpo- rativos, con el fin de determinar su transparencia ética y su relación con el ejercicio profesional contable, en el marco del cumplimiento de los fines establecidos por el Instituto Mexicano de Contadores Públicos (IMCP) y de los Colegios de Contadores Públicos de Perú, con énfasis en observar el respeto y cumplimiento de la norma de ética profesional. Admás incorpora información sobre los antecedentes y posiciones de diferentes filósofos, en relación a la ética, para identificar su relación con el ámbito profesional y empresarial actual. Asimismo, se considera pertinente incluir información sobre el estudio del Monitor Empresarial de Reputación Corporativa (Merco), para identificar a las empresas de Perú y México con mayor responsabilidad social durante los años 2016 y 2017, comparándolas con las empresas con mejor reputación, para después revisar algunas experiencias internacionales.

\section{Antecedentes}

El comportamiento de las personas, en particular, lo vinculado a la ética y a la moral, ha sido motivo de estudio durante muchos siglos y ha originado diversas posiciones por parte de investigadores y filósofos, considerando en algunos casos, enfoques filosóficos y en otros religiosos.

En general, la ética se define de acuerdo al lugar y contexto, es así que, en el siglo XXI, esta incorpora nuevos conceptos producto de cambios significativos en la sociedad, en la tecnología, y como parte del proceso de globalización en todos sus niveles, que se puede afirmar, origina impactos positivos y negativos, sobre todo, vinculado a la actividad empresarial privada. En la tabla 1 se presenta la evolución de la ética en la línea de tiempo, donde se puede observar que el estudio de la ética conserva su esencia desde la antigüedad, tal es así que, los pensadores de la Edad Antigua, centraban sus reflexiones en las acciones morales, 
orientadas a la felicidad. En la Edad Media se mantiene la misma línea, pero desde un enfoque filosófico y religioso; mientras que en la edad moderna, se profundiza desde el ámbito filosófico, en el cual prevalece la ética idealista que direcciona en dos aristas, el subjetivo (la idea solo existe en la mente del sujeto), y el objetivo (las ideas existen por sí mismas y solo podemos aprenderlas o descubrirlas). La época contemporánea, presenta diferentes posiciones orientadas a explicar la ética, como, la orientación positivista, marxista, o la pragmática. La ética en la actualidad, se orienta por la ética naturalista, heredada de Aristóteles, quien sostiene que la vida se conduce hacia el bien e implica actuar conforme a la naturaleza humana, lo cual lleva a adoptar nuevas dimensiones en lo moral, como responsabilidad social y respeto a la vida.
Desde la perspectiva teórica, la ética es un concepto transversal de distintas disciplinas, áreas, y momentos, respecto a la cual, diversos autores han estudiado y escrito sobre los sistemas morales, en busca del bien para lograr la estabilidad social y por lo tanto la felicidad. En este contexto, para González (1968), la ética es una "disciplina fundamental de la filosofía, que tiene por objeto el estudio de la conducta libre y responsable del hombre, orientada a la realización del bien, mediante el cumplimiento del deber, del que derivan determinadas consecuencias" ( $p$. 19). Asimismo, distingue a la moral como una "disciplina práctica que se refiere a la conducta del hombre tal y como ella es, tal y como se realiza, la ética estudia la conducta tal y como debe ser" (González, 1968, p. 20).

TABLA 1

Evolución de la ética

\begin{tabular}{|c|c|c|c|c|}
\hline No. & $\begin{array}{l}\text { Investigadores } \\
\text { y filósofos } \\
\text { representativos }\end{array}$ & Evolución & Periodo & Planteamiento \\
\hline 1 & $\begin{array}{l}\text { Aristóteles, } \\
\text { Platón, Sócrates }\end{array}$ & Edad Antigua & $\begin{array}{l}\text { Hasta el } \\
\text { siglo V }\end{array}$ & $\begin{array}{l}\text { Ética Nicomaquea en busca de la felicidad. } \\
\text { La reflexión se centra en las acciones morales. } \\
\text { Elegir y decidir qué hacer. }\end{array}$ \\
\hline 2 & $\begin{array}{l}\text { Alejandristas, } \\
\text { Nicolás Maquiavelo, } \\
\text { Giordano Bruno }\end{array}$ & Edad Media & $\begin{array}{l}\text { Siglo } \\
\mathrm{V}-\mathrm{XVII}\end{array}$ & $\begin{array}{l}\text { Ética Renacimiento, se explica desde el } \\
\text { enfoque religioso y filosófico. }\end{array}$ \\
\hline 3 & $\begin{array}{l}\text { Descartes, Kant, } \\
\text { Fichte, Mach, } \\
\text { Berkely }\end{array}$ & Edad Moderna & $\begin{array}{l}\text { Siglo } \\
\text { XVI- } \\
\text { XIX }\end{array}$ & $\begin{array}{l}\text { Prevaleció la ética idealista. } \\
\text { Clasificado en subjetivo (la idea solo existe en } \\
\text { la mente del sujeto) y objetivo las ideas existen } \\
\text { por sí mismas y solo podemos aprenderlas o } \\
\text { descubrirlas) }\end{array}$ \\
\hline 4 & $\begin{array}{l}\text { William } \\
\text { James, Arthur } \\
\text { Shopenhauer, Karl } \\
\text { Marx, Herber } \\
\text { Spencer }\end{array}$ & $\begin{array}{c}\text { Época } \\
\text { contemporánea }\end{array}$ & $\begin{array}{l}\text { Siglo } \\
\text { XIX-XX }\end{array}$ & $\begin{array}{l}\text { Diferentes posiciones orientadas } \\
\text { a explicar la ética. } \\
\text { Orientación positivista, marxista, pragmático. }\end{array}$ \\
\hline 5 & $\begin{array}{l}\text { Bernardo } \\
\text { Kliksberg, Rogelio } \\
\text { Soto, Ramón Ponce, } \\
\text { Santiago García }\end{array}$ & $\begin{array}{l}\text { Ética en la } \\
\text { actualidad }\end{array}$ & $\begin{array}{l}\text { Siglo } \\
\text { XXI }\end{array}$ & $\begin{array}{l}\text { Se orienta por la ética naturalista, heredada } \\
\text { de Aristóteles. Sostiene que la vida se conduce } \\
\text { hacia el bien e implica actuar conforme a la } \\
\text { naturaleza humana, lo cual implica adoptar } \\
\text { en la moral nuevas dimensiones, como } \\
\text { responsabilidad social y respeto a la vida. }\end{array}$ \\
\hline
\end{tabular}

Fuente: Autores. 
Contrastar las diferentes posiciones que tienen los autores respecto a una determinada teoría o concepto, nos permite identificar tendencias y/o coincidencias, así como situaciones antagónicas. En el caso de la ética, hemos identificado algunos autores representativos que han aportado al debate sobre este tema, en distintos momentos de las últimas décadas, información que es presentada en la tabla 2 .

En este sentido, Fagothey (1973) citado por Dextre, Perez y Prieto (1999) señalan que "la ética es el estudio de las costumbres fundamentales del ser humano, entre lo que está bien y lo que está mal por su parte" (p. 21) y Touraine (1992) profundiza

TABla 2

Posturas

\begin{tabular}{|c|c|c|c|}
\hline No. & $\begin{array}{l}\text { Autores } \\
\text { representativos }\end{array}$ & Período & Planteamiento \\
\hline 1 & $\begin{array}{l}\text { Real Academia } \\
\text { Española }\end{array}$ & $\because-$ & $\begin{array}{l}\text { Parte de la filosofía que trata del bien y del fundamento de sus } \\
\text { valores. }\end{array}$ \\
\hline 2 & González & 1968 & $\begin{array}{l}\text { La ética como disciplina de la filosofía, cuyo objeto de estudio es la } \\
\text { conducta libre y responsable del hombre, orientada a la realización } \\
\text { del bien, mediante el cumplimiento del deber, del que derivan } \\
\text { determinadas consecuencias (p. 19-20) }\end{array}$ \\
\hline 3 & $\begin{array}{l}\text { Austin } \\
\text { Fagothey }\end{array}$ & 1973 & $\begin{array}{l}\text { La ética es llamada también filosofía moral. Producto de su } \\
\text { derivación de la palabra, la ética es el estudio de las costumbres } \\
\text { fundamentales del ser humano. De analizar de lo que está bien y lo } \\
\text { que está mal, de lo bueno y lo malo en la conducta humana (p.2). }\end{array}$ \\
\hline 4 & $\begin{array}{l}\text { Alain } \\
\text { Touraine }\end{array}$ & 1992 & $\begin{array}{l}\text { La ética es la aplicación de principios morales; no sociales, a } \\
\text { situaciones creadas por la actividad social (p. 281). }\end{array}$ \\
\hline 5 & Foucault & 1987 & $\begin{array}{l}\text { Define a la ética como la elaboración de una forma de relación del } \\
\text { individuo consigo mismo que le permite constituirse en un sujeto de } \\
\text { conducta moral (p. 55). }\end{array}$ \\
\hline 6 & Maliandi & 1994 & $\begin{array}{l}\text { Es problematizar el ethos. En el lenguaje filosófico actual ethos se } \\
\text { usa para referirnos al conjunto de actitudes, convicciones, creencias } \\
\text { morales y formas de conducta, ya sea de una persona individual o } \\
\text { de un grupo social, o étnico. En líneas generales la ética es un modo } \\
\text { de reflexión que apunta principalmente a dos cosas: por una parte a } \\
\text { fundamentar las normas (o a cuestionar los fundamentos probables) } \\
\text { y por otra parte a aclarar lo mejor posible el sentido y el uso de los } \\
\text { términos propios del lenguaje moral (p. 11). }\end{array}$ \\
\hline 7 & $\begin{array}{l}\text { Dextre, } \\
\text { Perez y Prieto }\end{array}$ & 1999 & $\begin{array}{l}\text { La ética es una rama de la filosofía que estudia la vida moral de la } \\
\text { persona como un ser racional, es decir, su comportamiento libre, } \\
\text { desde sus primeras causas y principios en el orden natural. Toda } \\
\text { persona tiene dentro de sí el sentido del bien y del mal. Quiere hacer } \\
\text { el bien y evitar el mal. La ética estudia a la persona desde una } \\
\text { perspectiva total, universal, teórica que toma como objeto propio a } \\
\text { cada ser humano en abstracto. De otro lado, la ética es una ciencia } \\
\text { práctica, porque se refiere a los actos humanos, operables, y porque } \\
\text { busca dirigir la acción de los hombres y mujeres, de manera libre y } \\
\text { responsable, orientada al bien y alejada del mal (p. } 21) \text {. }\end{array}$ \\
\hline 8 & Chávez & 2014 & $\begin{array}{l}\text { Es una disciplina filosófica, cuyo objeto de estudio lo conforman los } \\
\text { problemas fundamentales de la moral, girando entorno de un valor } \\
\text { (bondad moral), producto de su investigación servirá como criterio y } \\
\text { fundamentos para que otras disciplinas formulen normas (p. 4) }\end{array}$ \\
\hline
\end{tabular}

Fuente: Autores. 
al señalar que "la ética es la aplicación de principios morales; no sociales, a situaciones creadas por la actividad social" (p. 281). Mientras que Foucault (1987, p. 55) define a "la ética como la elaboración de una forma de relación del individuo consigo mismo, que le permite constituirse en un sujeto de conducta moral". Para Maliandi (1994, p. 11) y Chávez (1994) "la ética es problematizar el ethos (actitudes, convicciones, creencias morales y formas de conducta, de un individuo o de un grupo social) a través de la reflexión orientada a fundamentar las normas y esclarecer el uso y sentido del lenguaje moral" (p. 4).

González (1968) clasifica la ética en dos partes: la primera se refiere a la ética teórica y la segunda a la ética aplicada. Esta última, como aquella que se lleva en la práctica, en la realidad. En la ética teórica hace un análisis amplio sobre la división de la moral, donde subraya los deberes del individuo para consigo mismo, los deberes para con los terceros, y los deberes para con Dios.

El análisis objetivo que realiza encara las responsabilidades que tiene el individuo, describiendo la moral teórica del individuo, y al mismo tiempo, la conducta en un hecho social del que surgen los conceptos fundamentales formales y materiales. La división ética o moral social que "comprende el estudio de los deberes del hombre" para con la sociedad, refiere el respeto para consigo mismo, para con los terceros y menciona los deberes para con Dios.

\section{Resultados}

\section{La normalización de la profesión contable}

Como parte del marcado proceso de globalización económica generado en las últimas décadas, la profesión contable se ha visto expuesta a una serie de cambios que la han llevado a la búsqueda de una estandariza- ción de la normatividad contable, requerida para la preparación de la información financiera de las empresas.

En este contexto, el ejercicio de la profesión contable también requiere de normas generales que regulen el actuar de los profesionales y su comportamiento ético, al momento de preparar la información financiera de las empresas, así como en todas las acciones que se relacionen directa o indirectamente con el ejercicio de la profesión.

En el ámbito internacional, el Consejo de Normas Internacionales de Ética para Contadores (International Ethics Standards Board of Accountants - IESBA), promulgó el Código de Ética para Profesionales de la Contabilidad, el cual cuenta con la adopción plena de ambos países, como miembros de la Federación Internacional de Contadores (IFAC, por sus siglas en inglés). En los siguientes párrafos se presenta la información relacionada con este Código y las normas gremiales o legales, que han permitido su adopción.

\section{El Código de Ética del IFAC ¿Reconstruyendo la confianza?}

La IFAC durante mucho tiempo ha trabajo con el objetivo de contar con normas que regulen el comportamiento ético en la profesión de la contaduría Pública en todos los países miembros. El desarrollo y difusión del Código de Ética Profesional, ha contado con la aceptación de varios países, como México y Perú, adoptado plenamente por el Instituto Mexicano de Contadores Públicos y por la Junta de Decanos de Colegios de Contadores Públicos de Perú (JDCCPP). Este Código de Ética Profesional contiene cinco principios fundamentales, la integridad, objetividad, diligencia y competencia profesional, confidencialidad y comportamiento profesional, los cuales, el Contador Público tiene la responsabilidad y obligación de asumir. 
La aplicación de estos principios, en el ejercicio profesional, hará que el desarrollo profesional del Contador Público sea íntegro y completo, y que su conducta sea el auspicio para la aplicación del marco conceptual y de las normas contables. El Código de Ética Profesional le permite identificar, evaluar y responder antes las amenazas de incumplimiento con los principios fundamentales y ayuda a cumplir con responsabilidad la conducta profesional para actuar en el interés público. El Código establece diferentes escenarios para reconocer las amenazas $^{1}$ de incumplimiento de los principios fundamentales, las cuales impiden que el Contador Público concluya que si una situación no está específicamente prohibida sea permitida.

El efecto de las amenazas administra con las salvaguardas, es decir, con acciones que pueden menguar, incluso, suprimir las amenazas o disminuirlas a un nivel tolerable. El Código divide a las salvaguardas en dos grandes categorías; salvaguardas creadas por la profesión, legislación o reglamento, y salvaguardas en el entorno del trabajo.

Las salvaguardas creadas por la profesión, legislación o reglamento, incluyen requisitos educacionales, de entrenamiento y de experiencia para ejercer la profesión: Requisitos de educación profesional continua; Reglas del gobierno corporativo; Normas profesionales; Procedimientos de monitoreo por un organismo profesional o por algún regulador y procedimientos disciplinarios; Revisión externa por un tercero con poderes legales, de los informes, relaciones, comunicaciones o información, producidos por el Contador Público.

\footnotetext{
${ }^{1}$ Las amenazas son los hechos y circunstancias que ponen en riesgo el cumplimiento de los principios fundamentales de la ética profesional (IFAC, 2012, párrafo 100.12).
}

\section{La regulación del Código de ética} en Perú

El organismo máximo representativo de la profesión de Contador Público en el Perú es la Junta de Decanos de Colegios de Contadores Públicos del Perú (JDCCPP), institución que, si bien no tiene la facultad para emitir normas en aspectos contables, tiene el reconocimiento legal y la potestad para establecer los mecanismos y normas que brinden el marco para la regulación ética de los que ejercen como Contador Público en el Perú, tanto en forma dependiente como independiente.

Perú, al ser país miembro del IFAC, y por recomendación de este organismo, dispone la adopción del Código de Ética Profesional actualizado en el año 2014, estableciendo como complemento, el Reglamento de Investigación y Disciplina (RID) aprobado en conjunto con el Código, los cuales deben ser de fiel cumplimiento por parte de todos los miembros de la profesión contable en Perú.

En la tabla 3 se describe las normas con las cuales se regula los aspectos relacionados al comportamiento ético del Contador Público en el Perú, estas disposiciones establecen el marco general y específico para el actuar del profesional contable, e incluyen situaciones desde la sanción moral hasta la sanción penal. Es una profesión que, mediante sus estatutos, establece las funciones, el accionar y el cumplimiento moral que debe cumplir el Contador Público que ejerce sus actividades en Perú.

La normativa a que se hace referencia en la tabla indicada, es publicada en las páginas Web de la JDCCPP y de los Colegios Profesionales departamentales que la integran, pero no se cuenta con evidencia de que estas normas sean difundidas entre todos sus asociados, de tal forma que tomen conocimiento de ellas y de las posibles sanciones a las que estarían expuestos, en caso de incumplimiento. 
TABLA 3.

Normas que regulan el comportamiento Ético del Contador Público en Perú.

\begin{tabular}{cll}
\hline $\mathrm{N}^{\circ}$ & \multicolumn{1}{c}{ Norma } & \multicolumn{1}{c}{ Referencia } \\
\hline \multirow{2}{*}{$\begin{array}{l}\text { Ley de profesionalización del Contador Público } \\
\text { y de creación de los colegios de contadores públicos }\end{array}$} & Ley 13253 de Septiembre de 1959 \\
2 & $\begin{array}{l}\text { Culpa inexcusable } \\
\text { Resolución 008-97-EF/93.01 (CNC, 1997) }\end{array}$ & \\
& $\begin{array}{l}\text { Ley de actualización de la Ley No. 13253, } \\
\text { de profesionalización del contador público } \\
\text { y de creación de los colegios de contadores públicos }\end{array}$ & Ley 28951 de Enero de 2007 \\
& $\begin{array}{l}\text { Código de Ética Profesional } \\
\text { del Contador Público Peruano }\end{array}$ & $\begin{array}{l}\text { Resolución 013-2005-JDCCPP. } \\
\text { Actualizado en 2015 }\end{array}$ \\
5 & $\begin{array}{l}\text { Cartilla del Manual del Código de Ética para } \\
\text { Profesionales de la Contabilidad (CMCEPC) }\end{array}$ & Resolución 009-2015-CD/JDCCPP (2015) \\
6 & $\begin{array}{l}\text { Reglamento de Investigación y Disciplina } \\
7\end{array}$ & $\begin{array}{l}\text { Guía del Manual del Código de Ética para } \\
\text { Profesionales de la Contabilidad - 2014 }\end{array}$ \\
8 & Código Penal, Decreto Legislativo 635 & JDClución 014-2015-CD/JDCCPP (2015) \\
\hline
\end{tabular}

Fuente: Autores.

\section{La regulación del Código de ética en México}

Por mucho tiempo en México el desarrollo de normas contables correspondió al Instituto Mexicano de Contadores Públicos (IMCP), así como también lo fue preparar normas de auditoría, y los principios de conducta ética del contador público antes de entrar en el proceso de convergencia. México, a través del IMCP, al ser miembro de la Federación Internacional de Contadores (IFAC, por sus siglas en inglés), se incorporó en el proceso de convergencia con las Normas Internacionales de Información financiera (NIIF, IFRS por sus siglas en inglés) y las Normas Internacionales de Auditoría (NIA). En el caso del Código de Ética Profesional la Comisión de Ética Profesional del Instituto Mexicano de Contadores Públicos decidió hacer adopción plena del código realizándose en el año 2012.

En materia legal la regulación del ejercicio profesional contable en México tiene su punto de partida en el Código Fiscal de la Federación, el cual exhorta a los Contadores Públicos Certificados (CPC), al cumplimiento de las Normas Internacionales de Auditoría para presentar el dictamen para efectos fiscales, de seguridad social, y de contribuciones locales bajo los principios de conducta ética. Este cumplimiento también es inmanente al dictamen financiero. Esta norma muestra los escenarios bajo los que se pueden afectar la independencia e imparcialidad, principios que están asociados a los principios fundamentales del Código de Ética Profesional. En la tabla 4 se describe esta y otras normas vigentes en México en torno al comportamiento ético.

El cumplimiento de la Norma de Educación Profesional Continua, fue establecido desde hace mucho tiempo. De igual manera, las autoras Hernández y Chumaceiro (2008) expresan que de forma ética y responsable

la educación y las instituciones que se le asocian como las universidades detentan la obligación de encabezar la generación y difusión de ese conocimiento, para ser abordado por todos los grupos y colectividades que le requieran, sobre todo aquellos que se incluyen en su radio de acción directo, tanto local, regional y nacional (p. 78). 
Así entonces, se define la Educación Continua como "la actividad educativa programada, formal y reconocida que el Contador Público llevará a cabo con el objeto de actualizar y mantener sus conocimientos profesionales en el nivel que le exige su responsabilidad social" y el cumplimiento de la norma es obligatoria para los socios del Instituto (IMCP, 2016). La manifestación sobre el cumplimiento de la Norma de Educación Profesional Continua para el Contador que se dedica al ejercicio profesional del sector independiente es de 55 puntos que deberán cubrirse con capacitación. Para los Contadores que se dedican al ejercicio profesional en los sectores académico, empresarial, gubernamental y otros, les corresponde 40 puntos que deberán cubrir con capacitación. En ambos casos deben de cubrir con 5 puntos de capacitación de la norma de ética profesional.

El 1 de mayo de 1998, entró en vigor el reglamento de Certificación para la práctica internacional de la contaduría emitido por el Comité Mexicano para la Práctica Internacional de la Contaduría Pública. Este organismo acuerda que el Instituto Mexicano de Contadores Públicos es la única entidad profesional con su respaldo para certificar a los contadores, en reconocimiento a la seriedad e institucionalidad de la organización (IMCP, 2016). El Contador Público Certificado (CPC) tiene que acreditar el dominio del conocimiento en las áreas de contabilidad (IFRS), auditoria (NIA), contabilidad y auditoría gubernamental, costos, finanzas, fiscal, seguridad social, comercio exterior, y ética y responsabilidades profesionales. Todo esto involucra el cumplimiento de las leyes, reglamentos y normas, y se reconoce que éstas tienen un carácter obligatorio, en particular los principios Éticos y responsabilidades profesionales, que incluye al Código de Ética Profesional, Norma de Control de Calidad y Norma de Desarrollo Profesional Continuo para la Certificación y posteriormente el refrendo de la certificación. Por ende, es responsabilidad del Contador Público acreditar anualmente el cumplimiento del Código de Ética Profesional para continuar en su calidad de Contador Público Certificado, distinción que lo hace competitivo internacionalmente. El cumplimiento para refrendar la certificación es de 65 puntos anuales que deberán cubrirse con capacitación, que incluye cinco puntos de la norma de ética profesional.

Es importante mencionar los requisitos éticos relevantes del párrafo 24 de la Norma de Control de Calidad (independencia), en el que se establece requerimientos para que el desempeño del Contador Público para llevar a cabo trabajos de auditoría y revisiones de información financiera, o trabajos de atestiguamiento, los mismos que se deben realizar bajo estándares internacionales. Asimismo, se indica que se requiere el establecimiento de controles y programas que soporten la calidad del trabajo que desempeña. Esta norma de Control de Calidad debe leerse en conjunto con el Código de Ética Profesional.

Otro aspecto relevante establecido en las leyes fiscales (Código Fiscal de la Federación), se refiere a las infracciones relacionadas con la presentación del Dictamen Fiscal que el Contador Público Certificado (CPC) presenta ante la autoridad hacendaria. Cuando este hecho se realice, y el auditor no observe la omisión de contribuciones del contribuyente debido al incumplimiento de la aplicación de las Normas de Auditoría que regulan la capacidad, independencia e imparcialidad profesional del Contador Público, el trabajo que desempeña y la información que rinde, es susceptible de la suspensión de su registro para dictaminar.

No se establece infracción cuando la omisión no supere el $15 \%$ de las contribuciones a cargo del contribuyente. Asimismo, al CPC que cometa las infracciones, se le aplicará la suspensión del registro para dictaminar por un periodo de tres años. 
Con relación al sector público se incorporó un código de ética para los servidores públicos al servicio de las dependencias y entidades de la Administración Pública Federal. En el código se establecen las reglas de integridad para el ejercicio de la función pública y los lineamientos generales para propiciar la integridad de los servidores públicos, de tal forma que se pueda implementar acciones permanentes que favorezcan su comportamiento ético, a través de los Comités de Ética y de Prevención de Conflictos de Interés, que regirán la conducta de los servidores públicos. La iniciativa de ley buscó que el documento consolidara a un gobierno más abierto al escrutinio público, con apego a los principios de legalidad, honradez, lealtad, imparcialidad y eficiencia, para fortalecer a las instituciones públicas y que a su vez responda a las necesidades de la sociedad, a fin de que sea acorde con los nuevos retos en materia de combate a la corrupción, y al mismo tiempo, el Estado promueva acciones para fortalecer la transparencia y la rendición de cuentas.
Como se puede apreciar en las tablas 3 y 4, la regulación del ejercicio de la profesión contable está presente en ambos países, con ciertos matices, observando una mayor regulación en el Perú, con énfasis en relación al Código de Ética, a través de un reglamento para su cumplimiento y una Guía para una mayor comprensión. Asimismo, es importante destacar que, desde el año 1991 en Perú, a través del Código Penal se sentencia la mala praxis del ejercicio profesional del Contador Público, el mismo que fue enfatizado en el año 1997 mediante el Consejo Normativo de Contabilidad (CNC).

\section{El Código de Ética del Contador Público y su impacto empresarial}

El incumplimiento de las normas éticas, en el actuar de todo profesional, tiene un impacto negativo en las organizaciones y en la sociedad en su conjunto. En este apartado se presenta un análisis del papel que han realizado los gremios profesionales y las instituciones del estado al respecto, así como su impacto en la actividad empresarial.

TABLA 4

Normas que regulan el comportamiento Ético del Contador Público en México.

\begin{tabular}{lll}
\hline No. & \multicolumn{1}{c}{ Norma } & \multicolumn{1}{c}{ Referencia } \\
\hline 1 & $\begin{array}{l}\text { Código Fiscal de la Federación. } \\
\text { Reglamento del Código Fiscal de la Federación }\end{array}$ & $\begin{array}{l}\text { Proceso Legislativo-Constitucional } \\
\text { Honorable Congreso de la Unión } \\
(2018)\end{array}$ \\
2 & Norma de Desarrollo Profesional Continuo (NDPC) & $\begin{array}{l}\text { Instituto Mexicano de Contadores } \\
\text { Públicos - IMCP (2016) }\end{array}$ \\
3 & Código de Ética Profesional (CEP) & $\begin{array}{l}\text { Instituto Mexicano de Contadores } \\
\text { Públicos - IMCP (2012) }\end{array}$ \\
& $\begin{array}{l}\text { Boletín Norma de Control de Calidad (NCC) Control } \\
\text { de calidad aplicable a las firmas de contadores públicos } \\
\text { que desempeñan auditorías y revisiones de información } \\
\text { financiera, trabajos para atestiguar y otros servicios } \\
\text { relacionados }\end{array}$ & $\begin{array}{l}\text { Instituto Mexicano de Contadores } \\
\text { Públicos - IMCP (2016) }\end{array}$ \\
5 & Código Fiscal de la Federación. & $\begin{array}{l}\text { Proceso Legislativo-Constitucional } \\
\text { Honorable Congreso de la Unión (2018) }\end{array}$ \\
6 & $\begin{array}{l}\text { Código de Ética de los Servidores Públicos del } \\
\text { Gobierno Federal. }\end{array}$ & $\begin{array}{l}\text { Proceso Legislativo-Constitucional } \\
\text { Honorable Congreso de la Unión (2015) }\end{array}$ \\
\hline
\end{tabular}

Fuente: Autores. 


\section{El papel de los colegios de contadores públicos en Perú}

Según las disposiciones vigentes, la JDC$\mathrm{CP}$ es el organismo encargado de velar, observar y sancionar el ejercicio profesional del Contador Público, a través de los respectivos colegios departamentales, los cuales cuentan con una comisión de ética. Por ejemplo, en el caso del Colegio de Contadores Públicos de Lima (CCPL), cuenta con una Comisión de Ética Profesional, la cual tiene como misión, velar por el buen comportamiento Ético de sus profesionales. Asimismo, según su función investigadora e informativa, contemplada en los artículos 54 y 77 del Estatuto y del Reglamento Inter$\mathrm{no}^{2}$, tiene como política fundamental garantizar un análisis de los casos recibidos con la mayor equidad, imparcialidad y justicia, así como velar por mantener el principio de reserva del procedimiento hasta la emisión del Informe final respectivo. En cuanto a la resolución de casos y las apelaciones que le eleve el Consejo directivo, estos se delegan al Tribunal de honor.

Como evidencia de las acciones que se llevan a cabo, tenemos como ejemplo el caso del Contador Público José Chancafe Liza, de la ciudad de Trujillo, quien en el año 2013 fue sentenciado a 8 años de prisión efectiva, por ser cómplice del delito de defraudación tributaria en la modalidad de uso indebido del crédito fiscal (RPP noticias, 2013).

Otro caso, en el mismo año, es la sentencia de la Corte Suprema de Justicia RN 3776-2013-Lima que afecta a los señores Lelio Balarezo Young, representante legal de la empresa BACONGESA, y al contador Acosta Santa Cruz, quienes actuaron de manera ilegal y dolosa con el fin de evadir impuestos, donde el contador, valiéndose de su profesión y de su función, elaboró la contabilidad registrando compras con com-

${ }^{2}$ Resolución 013-2005-JDCCPP (2015) y Resolución 0142015-CD/JDCCPP (2015) respectivamente. probantes falsos, incurriendo en la comisión de delito de defraudación tributaria a título de cómplice primario, según indicó la Corte Suprema (Gestión, 2015a).

En el año 2014, en la ciudad de Ancash, cuatro contadores públicos fueron sentenciados por haber incurrido en malas prácticas contables, luego de haber registrado operaciones inexistentes con documentos falsos, resultando en un menor pago del impuesto general a las ventas y del impuesto a la renta (Chimbote en línea, 2014).

En el año 2015, en la ciudad de Tacna, Carlos Fernández Arizapana fue sentenciado a siete años y diez meses por utilizar facturas falsas, con el fin de incrementar el crédito fiscal de su empresa Industrias Alimenticias Sol de los Andes E.I.R.L y así evadir el pago de impuestos y deducir gasto o costo para el impuesto a la renta de tercera categoría (Gestión, 2015b).

En el año 2016, en la ciudad de Tacna, la Sala Penal Superior de la Corte Superior de Justicia de Tacna condenó a cuatro años de prisión efectiva a los empresarios Oscar Mauricio Martorell Meneses y David Daniel Mercado Herrera por el delito de defraudación tributaria en agravio del Estado (RPP Noticias, 2016).

Los casos expuestos tienen como recurrente, el registro contable de operaciones falsas, en las cuales el Contador Público tiene responsabilidad, por ser parte inherente de sus funciones. Si bien es cierto que el Estado, mediante la administración tributaria, denuncia por estos hechos a los responsables directos, y que mediante la justica son sancionados, no se observa el papel activo de los colegios profesionales de Contadores Públicos en cumplimiento de sus fines, de acuerdo a ley ${ }^{3}$,

\footnotetext{
${ }^{3}$ Según el art. 5 de la Ley 28951 de 2007: los colegios de contadores públicos son instituciones autónomas... cuyos fines son los siguientes: a) Velar por el prestigio, desarrollo y competencias de la profesión. b) Fomentar el estudio... c) Cautelar el ejercicio profesional... d) Velar por el respeto y cumplimiento de las normas de ética profesional, entre otros.
} 
que lleve a aplicar sanciones y/o inhabilitaciones a los profesionales involucrados. Esto va acompañado de la ausencia de iniciativas constantes para realizar campañas para difundir una cultura ética e incentivar el cumplimiento del código y normas en pro de fortalecer el prestigio de la profesión contable.

\section{El papel del Instituto Mexicano de Contadores Públicos}

En México se han realizado reformas constitucionales para combatir la corrupción y evitar posibles conflictos de interés. Éstas buscan la prevención, detección, control, sanción, disuasión y combate a la corrupción. En estas acciones se involucra la profesión contable. Con ello se propicia que los ciudadanos fortalezcan su confianza en las instituciones, y en las organizaciones. En el ámbito público se busca siempre que los servidores públicos actúen en un marco de la legalidad y de las buenas prácticas, según versan los principios que éstos deberán aplicar (principios de legalidad, honradez, lealtad, imparcialidad, y eficiencia) y los valores constitucionales (de interés público, respeto, respeto a los derechos humanos, igualdad y no discriminación, equidad de género, entorno cultural y ecológico, integridad, cooperación, liderazgo, transparencia y rendición de cuentas) ${ }^{4}$. También se establecieron nuevas leyes para estructurar un Sistema Nacional

\footnotetext{
4 Principios constitucionales que todo servidor público debe observar en el desempeño de su empleo, cargo, comisión o función (Art. 4, fracción I y II, Acuerdo Código de Ética, 2015; Ley General de Responsabilidades Administrativas, 2016; Ley Federal de Responsabilidades de los Servidores Públicos 2013 Ley de Fiscalización y Rendición de Cuentas, 2010).
}

Anticorrupción ${ }^{5}$ (SNA), creando instituciones para formalizar el sistema legal. El Sistema Nacional se integra por el Comité Coordinador, el Comité de Participación Ciudadana, el Comité Rector del Sistema Nacional de Fiscalización y los Sistemas Locales $^{6}$.

En este contexto, surge el análisis del concepto de conflicto de interés. Y la Organisation for Economic Co-Operation and Development (OECD, 2003) ofrece una amplia descripción de las situaciones que permiten reconocer el fenómeno del conflicto de interés. Distingue tres diferentes tipos de conflictos: un conflicto de interés real, un conflicto de interés aparente, y un conflicto de interés potencial. Un conflicto de interés es cuando un funcionario público ha comprometido el adecuado desempeño de los deberes por el interés privado, fenómeno que puede ser llamado de mala conducta o abuso de autoridad. Si hubiera evidencia de corrupción entonces dejaría de llamarse un conflicto de interés.

El sistema legal (Ley Federal de Responsabilidades Administrativas de los Servidores Públicos ${ }^{7}$ ha establecido guías para identificar y prevenir conductas que

\footnotetext{
${ }^{5}$ El Sistema Nacional Anticorrupción es una instancia de coordinación entre distintas autoridades federales y estatales, que busca combatir eficazmente la corrupción. Tiene por objeto establecer principios, políticas públicas y procedimientos para la coordinación de las órdenes de gobierno en la prevención, detección y sanción de faltas administrativas y hechos de corrupción, así como el la fiscalización y control de los recursos públicos (Ley Orgánica de la Administración Pública Federal, 2017; Ley Orgánica de la Procuraduría General de la República (2016); Ley de Fiscalización y Rendición de Cuentas, 2010; Ley General del Sistema Nacional Anticorrupción, 2016).

${ }^{6}$ Art. 6, Acuerdo Código de Ética, 2015; Ley General de Responsabilidades Administrativas, 2016; Ley Federal de Responsabilidades de los Servidores Públicos, 2013.

7 A la fecha de entrada en vigor de la Ley General de Responsabilidades Administrativas, todas las menciones a la Ley Federal de Responsabilidades de los Servidores Públicos (2013) previstas en las leyes federales y locales, así como, en cualquier disposición jurídica, se entenderán referidas a la Ley General de Responsabilidades Administrativas (2016).
} 
puedan constituir un conflicto de interés. La ley define un conflicto de interés como aquella "situación que se presenta cuando los intereses personales, familiares o de negocios del servidor público puedan afectar el desempeño debido e imparcial de su empleo, cargo, comisión o funciones". También presume la "utilización indebida de información, abuso de funciones, contratación indebida, enriquecimiento oculto y ocultamiento de conflicto de interés, tráfico de influencias, corrupción, grados de parentesco”. Estas situaciones están plenamente identificadas y robustecidas por un marco jurídico que vuelve estas acciones inaceptables.

En el ámbito normativo contable y de la auditoría, las Guías de Control de Calidad para firmas de Auditoria (2011, p. 39) también definen un conflicto de interés. Menciona los escenarios que pueden surgir o configurarse en conflicto de interés. Por ejemplo, la firma de auditoría, cuando un socio o empleado representa a dos clientes, uno como parte compradora y otro como parte vendedora en la misma transacción, o si está ayudando a un cliente a contratar a una persona para un puesto de dirección y el socio o empleado sabe que el cónyuge de un miembro de la firma de auditoría está solicitando el puesto. O cuando los socios y empleados se aprovechan de información de los clientes para beneficio personal.

En esta misma área de conocimiento podemos estudiar el enfoque ético de un conflicto de interés que regula el Código de Ética Profesional (IMCP, 2012) de la Contaduría Pública. El código impone el uso a la profesión organizada de la palabra "deberá", esto es, la obligación de cumplir con la disposición específica, a menos que se prevalezca una excepción al Código. Esto nos lleva al principio fundamental de la Objetividad, donde ser objetivo es "evitar conflictos de interés o influencia indebida de terceros que afecten el juicio profesional o de negocios".
Entonces, un conflicto de interés es una amenaza a la objetividad, al juicio profesional, y a los otros principios fundamentales, y, por ende, a la aplicación de las normas contables y a la emisión de la información financiera. De acuerdo al Código de Ética Profesional (IMCP, 2012), ésta amenaza se crea cuando se lleva "un asunto en particular para dos o más partes cuyos intereses con respecto a dicho asunto están en conflicto”. En la profesión contable hay un fuerte vínculo de la ética profesional y el juicio profesional porque el profesional tiene que decidir sobre cómo aplicará la norma contable, atendiendo las situaciones específicas, buscando mostrar una información financiera confiable, veraz que presente la mejor posición financiera de la organización.

\section{Las empresas y su calificación ética}

La calificación ética de una empresa no guarda relación, necesariamente, con los resultados financieros y económicos que genera, hay otros aspectos que se debe tomar en cuenta. Para tal efecto, exis ten organismos sin fines de lucro que se dedican a evaluar, valorar y reconocer a aquellas empresas que han tenido un buen desempeño ético con responsabilidad social empresarial. En las siguientes líneas, presentamos algunos casos que muestran resultados respecto a la medición y calificación del comportamiento Ético de las empresas en Perú y México, así como a nivel mundial.

\section{- Las experiencias de Merco Perú}

Merco es un Monitor Empresarial de Reputación Corporativa, el cual elabora seis tipos de rankings. Uno de estos rankings se denomina Merco Responsabilidad y Gobierno Corporativo, el cual cuenta con una metodología multistakeholder que incluye cinco evaluaciones y doce fuentes de información. 
En Perú, Merco presentó sus resultados correspondientes al año 2017, en el que incluye a las 100 empresas que han obtenido una mejor evaluación en aspectos éticos y de responsabilidad y gobierno corporativo. En función a dicha información, en la Tabla $\mathrm{N}^{\circ} 5$ podemos observar las veinte primeras empresas de este ranking, en un comparativo de los años 2017 y 2016.

TABLA 5

Ranking MercoPerú de 20 primeras empresas.

\begin{tabular}{cccc}
\hline No. & Empresa & 2017 & 2016 \\
\hline 1 & Banco de Crédito del Perú & 1 & 1 \\
2 & Backus AB InBev & 2 & 2 \\
3 & Interbank & 3 & 3 \\
4 & Ferreyros & 4 & 5 \\
5 & Alicorp & 5 & 4 \\
6 & Pontificia Universidad & 6 & 7 \\
& Católica del Perú & & \\
7 & Natura Cosméticos & 7 & 15 \\
8 & Scotiabank & 8 & 30 \\
9 & Procter \& Gamble & 9 & 10 \\
10 & Rimac Seguros & 10 & 20 \\
11 & Kimberly - Clark & 11 & 8 \\
12 & BBVA Continental & 12 & 6 \\
13 & Pacíficos Seguros & 13 & 11 \\
14 & RPP & 14 & 12 \\
& (Radio Programas del Perú) & & \\
15 & Microsoft & 15 & 36 \\
16 & Universidad del Pacífico & 16 & 13 \\
17 & Cemtrum Católica & 17 & 16 \\
18 & Universidad ESAN & 18 & 67 \\
19 & Google & 19 & - \\
20 & AFP Integra & 20 & 21 \\
\hline
\end{tabular}

Fuente: Elaboración propia a partir de Merco (2017).

Las cinco evaluaciones que considera el ranking, son: encuesta a directivos, evaluación de expertos, evaluación de méritos, merco consumo y merco talento. Para tal efecto, se considera distintos ángulos, observando conductas éticas, centrado en lo social, económico y medioambiental, entre otros factores.
Los resultados del ranking nos muestran que las empresas con mejor evaluación en responsabilidad y gobierno corporativo, se ubican en sectores como el financiero, educación, industrial y comunicaciones. Asimismo, los resultados del año 2017, nos muestran algunos cambios en las diez primeras posiciones, en las cuales, las empresas Graña y Montero y Gloria han sido excluidas. Esta situación guarda coherencia con la coyuntura, en la cual, Graña y Montero se vio involucrada en denuncias de sobornos en el caso Odebrecht, lo que originó una caída de hasta $73 \%$ en el valor de sus acciones en la Bolsa de Valores de Lima y en la Bolsa de Nueva York (RPP Noticias, 2017). En el caso de la empresa Gloria, esta incurrió en publicidad engañosa, donde el Instituto Nacional de Defensa de la Competencia y de la Protección de la Propiedad Intelectual (INDECOPI), señaló que la compañía inducia al error a los consumidores, en algunos de sus productos (Gestión, 2017).

Ambos casos se encuentran en proceso de investigación, no obstante, la imagen de ambas empresas se encuentra menoscabadas con un impacto económico importante. El análisis va por si estas compañías evaluaron y aplicaron la ética en función a los valores y principios corporativos. A su vez, cabe preguntarnos, sí los contadores de dichas compañías reflejaron la realidad económica de acuerdo a los principios y normas contables en cumplimiento del Código de Ética Profesional.

\section{- Las experiencias de Merco México}

En México, las empresas con mejor evaluación en responsabilidad y gobierno corporativo se encuentran en primer lugar, según el sector donde se desarrollan, de acuerdo con el ranking de MercoMéxico. Por ejemplo, en alimentación, el Grupo Bimbo encabeza la lista como la empresa con mejor calificación (10000 puntos); en el sector automotriz, General Motors (7929 puntos); en el sector de Autoservicios y departamentales, Wal- 
mart (7995 puntos); en bebidas, Coca Cola (9131 puntos); el líder del sector económico de Conglomerados es Femsa (8432 puntos); en el sector farmacéutico, Faizer (7377 puntos); en el sector financiero, BBVA Bancomer (7761 puntos); en el sector industrial P\&G (8199 puntos); y en el sector de Tecnologías de la información, la empresa Google (8835 puntos). Es decir, nueve de las veinte primeras empresas (Tabla 6) que gozan de mayor responsabilidad social y gobierno corporativo en México son líderes del sector.

TABLA 6

Ranking MercoMéxico de 20 primeras empresas.

\begin{tabular}{cccc}
\hline No. & Empresa & 2017 & 2016 \\
\hline 1 & Grupo Bimbo & 1 & 1 \\
2 & Google & 2 & 4 \\
3 & Coca Cola México & 3 & 2 \\
4 & Grupo Modelo & 4 & 3 \\
5 & P\&G & 5 & 5 \\
6 & FEMSA & 6 & 8 \\
7 & PEPSICO & 7 & 6 \\
8 & Grupo Danone & 8 & 31 \\
9 & Cemex & 9 & 42 \\
10 & Cm/Heineken México & 10 & 35 \\
11 & Grupo Carso & 11 & 14 \\
12 & Walmart & 12 & 10 \\
13 & Microsoft & 13 & 9 \\
14 & Samsung & 14 & 30 \\
15 & Apple & 15 & 11 \\
16 & Nestlé & 16 & 13 \\
17 & Telefónica & 17 & 36 \\
18 & BBVA Bancomer & 18 & 17 \\
19 & Citibanamex & 19 & 18 \\
20 & KELLOGGS & 20 & 26 \\
\hline
\end{tabular}

Fuente: Elaboración propia a partir de Merco (2017). .

Cabe mencionar que los dos últimos años el Grupo Bimbo, se ha mantenido en la misma posición. En relación al Grupo Modelo y Google pasaron del segundo lugar al tercero, y del tercero al cuarto, respectivamente. Es importante subrayar que, así como Grupo
Bimbo es la empresa con mejor reputación corporativa en 2017, también lo es su líder, Daniel Servitje, el líder con mejor reputación (10000 puntos) según el ranking de MercoMéxico. Le sigue José Antonio González Carbajal de Femsa (8871 puntos), y María Teresa Arnal de Google (8454 puntos). Coca Cola México tuvo el primer lugar en el 2016 y para el siguiente año descendió al cuarto lugar. P\&G y Microsfot fueron empresas que tuvieron la misma experiencia.

\section{- Algunas experiencias globales}

El referente internacional, conocido como índice de Percepción de la Corrupción 2016 de Transparency International, revela la percepción de los niveles de corrupción en los países y mide las variables de gobierno abierto, rendición de cuentas, libertad de expresión, transparencia, niveles de integridad en el servicio público y acceso igualitario a la justicia. Los datos de este informe muestran que "ninguno de los 176 países o territorios obtuvo una calificación perfecta. Más de dos tercios de las naciones examinadas se encuentran por debajo de la media de la escala que se utilizó para medir la percepción de la corrupción. Es decir, la calificación promedio de todos los países fue de 43 , lo cual indica un alto grado de percepción de corrupción alrededor del mundo" (IMCO Staff, 2016) ${ }^{8}$, es decir, ningún país es transparente al cien por ciento.

Otra experiencia similar, es la del Instituto Ethisphere (2017), institución mundial con sede en Nueva York, que tiene como propósito promover mejores prácticas corporativas y definir los estándares de prácticas comerciales éticas. El año 2017 publicó la lista de las empresas consideradas como las más éticas del mundo, las que ascienden a

\footnotetext{
8 Transparencia internacional citado por IMCO Staff (2016) publica sobre los países más transparentes que están conformados por los mismos países que el año anterior: Dinamarca, Nueva Zelanda, Finlandia y le siguen Suecia, Suiza, Noruega, Singapur, Países Bajos, Canadá y Alemania
} 
135 compañías ubicadas en los cinco continentes, en diecinueve países que pertenecen a cincuenta y dos sectores económicos. En la lista se encuentran trece empresas que han sido once veces ganadoras y ocho premiadas. Cabe resaltar que en este reconocimiento se encuentran dos países latinos, México, representado por Bimbo, y Brasil, representado por Natura. Este ranking considera la correspondencia entre la existencia de un programa de ética y cumplimiento en la empresa, su reputación, la cultura ética, el gobierno corporativo y la responsabilidad social.

El Covalence EthicalQuote Ranking (s/f), descrito por Gómez (2012), es una firma de investigación ubicada en Geneva, Switzerland, que mide la reputación de las empresas. Recientemente publicó un informe con las corporaciones con mayor grado de ética empresarial en el mundo, en el que destacan, Newsweek magazine Dell y DuPont. La segunda ha sido denominada como una de los líderes con mayor reputación ética, además se ubica en el número diez de la industria y es una de las primeras quinientas compañías multinacionales. Por otro lado, L’Oréal se colocó en el primer lugar de la industria personal y de artículos para el hogar, y el octavo a nivel mundial. Asimismo. Se clasificó a Verizon como la segunda compañía ética en la industria de la telecomunicación.

El informe también excluye a empresas que no califican con un buen grado de ética empresarial, por ejemplo, no se distingue a Monsanto por "prácticas que prostituyen la alimentación de los pueblos y experimentan con la salud de los seres humanos a través de cuestionables productos alimenticios genéticamente manipulados". Otro caso es el de Chevron, la empresa "petrolera se ha caracterizado por infringir" leyes ambientales, y ha sido señalada como evasora fiscal. Ryanair, aerolínea árabe irlandesa que ha impuesto una agresiva política para abatir costos prohibiendo a sus empleados “utilizar los bolígrafos de la compañía o cargar sus teléfonos celulares utilizando los enchufes eléctricos". Philip Morris International Inc "ha buscado manipular a su favor las leyes" "[...] para regular el consumo de tabaco en distintas naciones. Freeport-McMoRan, empresa "productora de cobre y oro se ha apropiado, en contra de la población local, de los yacimientos de oro más grandes del mundo ubicados en Indonesia”. Grupo México, empresa extractora de minas mexicanas ha gastado cantidades importantes de dinero para sostener un "litigio contra sus propios trabajadores [...] luego de que impulsaran una huelga por las pésimas condiciones laborales".

\section{Conclusiones}

La ética ha evolucionado al unísono del desarrollo social y empresarial, tal es así, que, en la actualidad, toma mayor fuerza y relevancia la responsabilidad social empresarial, como un reflejo de la ética evolucionada aplicada a la actividad empresarial.

Los gremios profesionales de contadores públicos deben cumplir sus fines y promover mediante campañas permanentes de difusión, las diferentes normativas y reglamentación respecto al comportamiento Ético de la profesión contable. Para tal efecto, los responsables encargados de su conducción deben de actuar con imparcialidad.

La línea entre el bien y el mal es cada vez más fina, donde la sociedad en su conjunto, llega a pasar por alto los actos de corrupción, los cuales van en aumento en los diferentes niveles políticos, empresariales y profesionales. No obstante, la esperanza aún no se pierde, toda vez que existen personas y organizaciones que nos resistimos $\mathrm{y}$ creemos que, mediante el fortalecimiento de nuestros valores morales, actuando en coherencia en nuestra sociedad, vamos, no solo a fortalecer la imagen de nuestra profesión, sino replicar en otras situaciones sociales. 
Ante la acometida que tienen los profesionales de la contaduría pública de presentar información financiera veraz y confiable, es necesario una reflexión sobre la oleada de conductas inapropiadas que las personas dejan plasmadas en las organizaciones. Es importante tomar conciencia, y emprender acciones, en relación a la formación en principios y valores, desde el hogar, base principal de la formación del individuo, hasta la formación universitaria, en la cual debe incluirse un enfoque transversal de la ética en el currículo.

Existen entornos jurídicos y regulatorios, discrecionales y estables, que, al aplicarse en una situación real, y no dar cumplimiento, se violentan los derechos. Este fenómeno provoca que el entorno se vuelva débil, mostrando un grado de inseguridad jurídica que abre paso a la impunidad, porque implica delitos que jamás serán llevados a la justicia, o no pueden ser probados, o si lo fueran, quedarían sin la pena justa. Estas situaciones evidencian un débil Estado de Derecho, el cual infiere un sometimiento de los poderes del estado a la razón.

En la contaduría pública, aplicar los valores éticos en el ejercicio profesional y en las organizaciones, es intrínseco, porque en la generalidad, los informes financieros que se presenten contienen el juicio profesional del experto en normas contables, sin hechos o situaciones que desvirtúen la realidad. Juicio y ética profesional deben de aplicarse conjuntamente para generar una excelente información financiera.

Finalmente, reconocer lo plausible que son las organizaciones que tienen una mejor responsabilidad social corporativa, más aún, cuando éstas son dirigidas por un líder que también se ubica en los primeros puestos de los mismos rankings. Esto demuestra la congruencia de una organización y el liderazgo, como evidencia de la incidencia de una conducta ética en las organizaciones.

\section{Referencias}

Alvarez-Gayou. (2003). Cómo hacer investigación cualitativa. México, D.F.: Paidós.

Brown, T. (1992). La ética en la empresa. Estrategias para la toma de decisiones. Barcelona: Paidós.

Covalence EthicalQuote (s/f). Corporate Testimonies. Covalence EthicalQuote Ranking. Recuperado de http://www. ethicalquote.com/index.php/clients/corporate-testimonies/.

Chávez P. (2014). Ética. México D.F.: Editorial Patria.

Chimbote en línea (mayo 15, 2014). Cuatro contadores públicos en prisión por evadir impuestos a la SUNAT. (Locales). Recuperado de http://chimbotenlinea. com/locales/15/05/2014/cuatro-contadores-publicos-en-prision-por-evadirimpuestos-la-sunat

Chumaceiro, A. y Hernández, J. (2016). Países generadores de políticas públicas para el fomento de la cultura empresarial dirigida hacia la responsabilidad social. Revista Telos, 18(1). 103-120. Disponible en http://ojs.urbe.edu/index. php/telos/article/view/790

Dextre, J., Perez, P. y Prieto, F. (1999). Ética del desarrollo personal y social. Bases para la formación moral de la persona. Lima: Editorial Realidades.

Ethisphere. (2017). World's Most Ethical Companies, Honorees. Recuperado de: http://worldsmostethicalcompanies. ethisphere.com/honorees/

EUM. Congreso de la Unión. (25 de junio de 2018). DECRETO por el que se reforma el artículo 69-B del Código Fiscal de la Federación. [Código Fiscal de la Federación]. DOF: DCCLXXVII No. 24. Disponible en http://www.dof.gob.mx/ nota_detalle.php?codigo $=5528960 \&$ fec ha $=25 / 06 / 2018$ 
EUM. Congreso de la Unión. (19 de mayo de 2017). DECRETO por el que se reforman y adicionan los artículos 30 de la Ley Orgánica de la Administración Pública Federal y 2 de la Ley Orgánica de la Armada de México. [Ley Orgánica de la Administración Pública Federal]. DOF: Tomo DCCLXIV No. 14. Disponible en http://dof.gob.mx/nota_detalle. p h p ? c od i g o $=5483676$ \& f e c ha $=19 / 05 / 2017$

EUM. Congreso de la Unión. (18 de julio de 2016). DECRETO por el que se reforman y adicionan diversas disposiciones de la Ley Orgánica de la Procuraduría General de la República. [Ley Orgánica de la Procuraduría General de la República]. DOF: Tomo DCCLIV No. 14. Disponible en http://dof. gob.mx/nota_detalle.php?codigo $=5445$ 050\&fecha $=18 / 07 / 2016$

EUM. Congreso de la Unión. (18 de julio de 2016). DECRETO por el que se expide la Ley General del Sistema Nacional Anticorrupción; la Ley General de Responsabilidades Administrativas, y la Ley Orgánica del Tribunal Federal de Justicia Administrativa. [Ley General del Sistema Nacional Anticorrupción]. DOF: Tomo DCCLXXVIII No. 14. Disponible en http://www.dof.gob.mx/ nota_detalle.php?codigo $=5445048 \& f e c$ ha $=18 / 07 / 2016$

EUM. Congreso de la Unión. (18 de julio de 2016). DECRETO por el que se expide la Ley General del Sistema Nacional Anticorrupción; la Ley General de Responsabilidades Administrativas, y la Ley Orgánica del Tribunal Federal de Justicia Administrativa. [Ley General de Responsabilidades Administrativas]. DOF: Tomo DCCLXXVIII No. 14. Disponible en http://www.dof.gob.mx/ nota_detalle.php?codigo $=5445048 \& f e c$ ha $=18 / 07 / 2016$
EUM. Secretaría de la Función Pública. (20 de agosto de 2015). Acuerdo que tiene por objeto emitir el Código de Ética de los servidores públicos del Gobierno Federal, las Reglas de Integridad para el ejercicio de la función pública, y los Lineamientos generales para propiciar la integridad de los servidores públicos y para implementar acciones permanentes que favorezcan su comportamiento ético, a través de los Comités de Ética y Prevención de Conflictos de Interés. [Código de Ética de los servidores públicos del Gobierno Federal]. DOF: Tomo DCCXLIII No. 14. Disponible en http://dof.gob.mx/nota_detalle. p h p ? c od i g o $=5404568 \&$ f e c ha $=20 / 08 / 2015$

EUM. Congreso de la Unión. (24 de diciembre de 2013). DECRETO por el que se adiciona la fracción XXI bis al artículo 47 de la Ley Federal de Responsabilidades de los Servidores Públicos. [Ley Federal de Responsabilidades de los Servidores Públicos]. DOF: DCCXXIII No. 19. Disponible en http:// www.secretariadoejecutivo.gob. $\mathrm{mx} /$ docs/pdfs/normateca/Leyes/ley_federal_responsabilidades.pdf

EUM. Congreso de la Unión. (18 de junio de 2010). Decreto por el que se reforma el primer y segundo párrafos del artículo 16, de la Ley de Fiscalización y Rendición de Cuentas de la Federación. [Ley de Fiscalización y Rendición de Cuentas de la Federación]. DOF: DCLXXXI No. 14. Disponible en https:// w w w.uv.mx / contralori a / files/2013/02/1.-Ley-Federal-de-Fiscalizacion-Superior-de-la-Federacion.pdf

Fagothey, A. (1973). Ética teoría y aplicación. California: Interamericana S.A.

Foucault, M. (1987). La ética del pensamiento. Editorial biblioteca nueva. 
Gestión. (abril 24, 2015a). Caso Balarezo. (Redacción). Recuperado de https://gestion.pe/economia/balarezo-construcciones-inflo-facturas-s-9-s-751-000-87324

Gestión. (julio 7, 2015b). Comerciantes de Tacna y Juliaca irán a prisión por contrabando y defraudación tributaria. [Redacción]. Recuperado de https://gestion. pe/economia/comerciantes-tacna-juliacairan-prision-contrabando-defraudaciontributaria-93990

Gestión. (junio 5, 2017). Caso Gloria. [Redacción]. Recuperado de https://gestion. pe/economia/empresas/caso-gloria-publicidad-enganosa-peru-136561

Gómez, N. (marzo 8, 2012). Empresas sin ética. La Jornada. [Opinión]. Recuperado de http://www.jornada.unam.mx/2012/03 /08/opinion/024a1pol

González, F. (1968). Ética Social. México, D.F.: Porrúa.

Hernández, J. y Chumaceiro, A. (2008). Sociedad del conocimiento y pertinencia social universitaria. CEISEP una propuesta para la UNERMB. Revista Venezolana de Ciencias Sociales, UNERMB, 12(1). 77-92.

IFAC (2012). Código de Ética de IFAC. New York: International Federation of Accountants. Recupeado de https://www.ifac. org/system/files/publications/files/codigode-etica-para-profesionales-de-la-contabilidad.pdf

IMCO Staff. (2016). Índice de Percepción de la Corrupción 2016. Transparencia Internacional. Recuperado de http://imco.org. mx/politica_buen_gobierno/45206indicede-percepcion-de-la-corrupcion-2016-viatransparencia-internacional/

IMCP (2016). Normas Internacionales de Auditoría. México, D.F.: Instituto Mexicano de Contadores Públicos.

IMCP (2012). Código de Ética Profesional. México, D.F.: Instituto Mexicano de Contadores Públicos.
JDCCPP. (11 de diciembre de 2015). Reglamento de investigación y disciplina. (Resolución 014-2015-CD/JDCCPP).

JDCCPP. (4 de agosto de 2015). Código de Ética Profesional del Contador Público Peruano. [Resolución 013-2005-JDCCPP].

JDCCPP. (31 de agosto de 2015). Cartilla del manual del Código de Ética para Profesionales de la Contabilidad (CMCEPC). [Resolución 009-2015-CD/ JDCCPP].

JDCCPP. (septiembre, 2015). Guía del manual del Código de Ética para Profesionales de la Contabilidad-2014. Recuperado de http://www.jdccpp.com/ docs/GUIA-DEL-MANUAL-DEL-CODIGO-DE-ETICA-PARA-CONTADORES.pdf

Maliandi, R. (1994). Ética: conceptos y problemas. Buenos Aires: Biblos

Merco (2017). Mercoempresas: las empresas con mejor reputación corporativa. Recuperado de http://www.merco.info/ pe/ranking-merco-empresas

OECD. (2003). Managing Conflict of Interest in the Public Service. OECD Guidelines and Country experiences. París: OECD. Recuperado de http://www. oecd.org/governance/ethics/48994419. pdf

República de Perú. CNC. (23 de enero de 1997). Precisa obligaciones de los Contadores Públicos en el ejercicio de la prestación de sus servicios profesionales. [Resolución 008-97-EF/93.01]. El Peruano 26/01/1997.

República de Perú. Presidencia de la República. Congreso de la República. (3 de abril de 1991). Por el que se promulga el Código Penal, aprobado por la Comisión Revisora constituída por la ley núm. 25280. [Decreto Legislativo 635]. El Peruano 1991-04-10. 
República de Perú. Presidencia de la República. Congreso de la República. (15 de enero de 2007). Ley de actualización de la Ley No. 13253, de profesionalización del Contador Público y de creación de los Colegios de Contadores Públicos. [Ley 28951]. El Peruano 16030-2. Recuperado de http://www.leyes.congreso.gob.pe/Documentos/Leyes/28951.pdf

República de Perú. Presidencia de la República. Congreso de la República. (11 de septiembre de 1959). Ley de profesionalización del Contador Público y de creación de los Colegios de Contadores Públicos. [Ley 13253]. Recuperado de http://www. leyes.congreso.gob.pe/Documentos/Leyes/13253.pdf

RPP Noticias (diciembre 4, 2017). Los 7 golpes que sufrió Graña y Montero por el caso Odebrecht. [Redacción]. Recuperado de http://rpp.pe/economia/economia/los7-golpes-que-sufrio-grana-y-monteropor-el-caso-odebrecht-noticia-1092474

RPP Noticias (enero 11, 2016). Sentencian a cuatro años de prisión a dos empresarios por defraudación tributaria. [Redacción]. Recuperado de http://rpp.pe/economia/ economia/sentencian-a-cuatro-anos-deprision-a-dos-empresarios-por-defraudacion-tributaria-noticia-928740

RPP Noticias (agosto 12, 2013). Contador es sentenciado a 8 años de cárcel por defraudación tributaria. [Redacción]. Recuperado de http://rpp.pe/economia/economia/ contador-es-setenciado-a-8-anos-de-carcel-por-defraudacion-tributaria-noticia- 621436

Touraine, A. (1992). Critica de la modernidad. Paris: Librairie Arheme Fayard.

Wolf, T. y Gürgen, E. (2012). Mejora de la gestión pública y lucha contra la corrupción en los países bálticos, y de la CEI: La función del FMI. Washington, D.C.: International Monetary Fund. Recuperado de http://www.imf.org/external/pubs/ $\mathrm{ft} /$ issues/issues21/esl/issue21s.pdf.
María Enriqueta Mancilla-Rendón es Doctora en Ciencias de la Administración por la Universidad Nacional Autónoma (México) con Maestría en Administración por la Escuela Bancaria y Comercial (México). Contadora pública por la Escuela Bancaria y Comercial (México) e Investigadora de la Facultad de Negocios de la Universidad La Salle México (México).

Oscar Alfredo Díaz-Becerra es candidato a Magister en Contabilidad con mención en Gestión por la Universidad Nacional Mayor de San Marcos (Perú) y Contador Público por la Pontificia Universidad Católica (Perú). Bachiller en Ciencias Administrativas por la Pontificia Universidad Católica (Perú) y docente a tiempo completo en el Departamento de Ciencias Contables de la Pontificia Universidad Católica (Perú).

Lorenza Morales Alvarado es Doctorando en Contabilidad con mención en Política Fiscal por la Universidad Nacional Mayor de San Marcos (Perú) con Magíster en Contabilidad Internacional por la Universidad de Buenos Aires (Argentina) y Magíster en Administración por la Universidad Garcilaso de la Vega (Perú). Contador Público por la Universidad Nacional del Callao (Perú) y Docente de la Universidad Continental (Perú). 